\title{
LXI. On a method of measuring very small intervals of time
}

\author{
Mr. Robert Sabine
}

To cite this article: Mr. Robert Sabine (1876) LXI. On a method of measuring very small intervals of time, Philosophical Magazine Series 5, 1:5, 337-346, DOI: 10.1080/14786447608639051

To link to this article: http://dx.doi.org/10.1080/14786447608639051

曲 Published online: 13 May 2009.

Submit your article to this journal $\lceil\pi$

Џ Article views: 2

Q View related articles $\square$

Citing articles: 1 View citing articles $\square$ 
LONDON, EDINBURGH, AND DUBLIN

\section{PHILOSOPHICAL MAGAZINE \\ AND}

\section{JOURNAL OF SCIENCE.}

\section{[FIFTH SERIES.]}

\section{$M A Y 1876$.}

XLI. On a Method of Measuring very smail Intervals of Time. By Mr. RoberT SABINE* .

THE method I am going to describe of determining any 1 very small interval of time which elapses between two successive mechanical actions, I believe to be trustworthy when proper precautions are used. It is based upon the fact that a charged Leyden jar or other form of accumulator $t$ can only be discharged at a certain definite rate through a given circuit.

It is common knowledge that if a telegraph cable or accumulator have an electrostatic capacity of $f$ farads, and the resistance to leakage or discharge between its two sides be $R$ ohms, the time ( $t$ seconds) required for any initial charge of the potential $\mathbf{P}$ to diminish to a remainder at the potential $p$ will be

$$
t=f \mathrm{R} \log _{\varepsilon} \frac{\mathrm{P}}{p} \text { seconds, }
$$

assuming that all the electricity which we have to deal with resides upon the coatings and that it is free to be discharged. This proportion, otherwise expressed, is commonly used for finding the insulation resistances of submarine cables when their capacities are known and the initial charge is allowed to leak or discharge through the dielectric alone during a given number of minutes.

In employing this method for the measurement of time, it is

Communicated by the Author.

+ Commonly called a " condenser."

Phil. Mag. S. 5. Vol. 1. No. 5. May 1876. 
necessary to know exactly the value of the resistance; and as this could not be depended upon if the discharge took place through the dielectric, a known wire resistance, $r$, has to be inserted between the two sides of the accumulator, so that the time during which the potential $\mathrm{P}$ of the charge falls to $p$ is

$$
t=\frac{f \log _{\mathrm{e}} \frac{\mathrm{P}}{p}}{\frac{r+\mathrm{R}}{r \mathrm{R}}} \text { seconds. }
$$

The internal or insulation resistance $\mathrm{R}$ of the accumulator being made so great in comparison with $r$ that it may practically be regarded as infinite* , the time is then expressed by

$$
t=f r \log _{e} \frac{\mathrm{P}}{p} \text { seconds. }
$$

Assuming that the excursion of the light-point of a mirrorgalvanometer is proportional to the quantity of electricity suddenly discharged through its coil, if the excursions are respectively $\mathrm{C}$ and $c$, the time is

$$
t=f r \log _{e} \frac{\mathrm{G}}{c} \text { seconds. }
$$

The only values therefore required to be known are the capacity $(f)$ of the accumulator, and the resistance $(r)$ of the discharging wire. The measurement is independent of the constant of sensibility of the galvanometer and of the electromotive force of the battery, neither of which, however, must vary during an observation.

I have employed this system to determine the intervals of time which elapse and

(1) Between the successive interruptions of two circuits,

(2) Between making and breaking a single circuit.

The interval of time to be measured is, of course, always that during which the accumulator is allowed to partially empty itself through the discharging resistance.

When the time to be measured is that which elapses between the successive interruptions of two circuits, the apparatus is arranged in principle as is shown in fig. 1. The two circuits

* With a mica accumulator of $\frac{1}{9}$ microfarad capacity, the discharging resistance, $r$, necessary for determining intervals of time between $\tau_{1}^{\frac{1}{0}} \overline{0}$ and $\frac{1}{10}$ of a second is under 1 megohm. The internal resistance of such an accumulator is considerably over 200,000 megohms, so that practically it may be assumed to be in all cases infinite in comparison with $r$. 
which have to be broken are $a$ and $b$,-first $a$, then $b$. In the figure, $a$ and $b$ are supposed to represent, by way of illustration, two thin wires stretched at different distances fromthe muzzle, $B$, of a gun in such a way that the shot passes through them in the direction of the arrows. The battery $\mathrm{E}$ has so little resistance* in comparison with that of the discharging wire $r$, that the potential of the accumulator, A, remains practically unaltered when $r$ is made infinite.

A key of peculiar construction is convenient for observing the initial charge. It consists of a lever $(K)$ turning on pivots

Fig. 1.

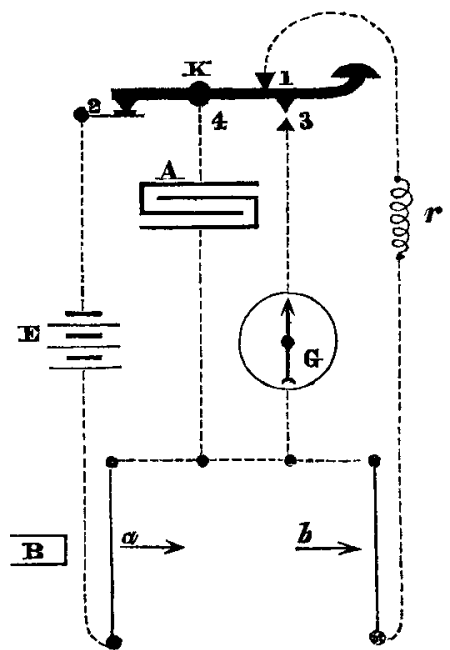

at 4. When in its position of rest (as shown in the figure) the rigid contact, 1, at the top in front, and the spring contact, 2 , underneath at the back, are both in connexion with the lever. When the knob is depressed the rigid contact 1 is first interrupted; an instant afterwards the spring contact, 2, is interrupted; and lastly the front contact, 3 , is made. This arrangement ensures the removal of the discharging resistance $r$, before the interruption of the battery, by the key.

Depressing for a moment the knob of the key, the resistance and battery are therefore successively interrupted, and the instantaneous discharge from the accumulator is read off by the excursion of the galvanometer-needle at $G$. This gives the value $\mathrm{C}$.

Letting the key resume its position of rest and recharge the accumulator, the wires $a$ an $d b$ are in turn interrupted by firing a shot through them. The interruption of $a$ puts the battery out of action; and the charge which is in the accumulator at the moment commences to flow out through the discharging wire $r$. This flow is stopped as soon as the shot reaches and breaks $b$. The observer, as soon as he hears the report, depresses the key and reads the excursion $(c)$ of the needle due to the remainder of the charge.

The accuracy of this method depends upon the conditions (1) that the difference of potential between the two sides of the accumulator is not altered practically by its poles being

* A single cell of Daniell's battery of large surface is sufficient. 
joined by the discharging wire, and (2) that the time which elapses between the interruption of the circuit $b$ and the pressing down of the key is not sufficient to allow of any loss through the dielectric. Further on I will show how nearly these conditions may be secured.

It is, of course, necessary to have every part of the apparatus as well insulated as possible; and it is desirable that the discharging resistance and a shunt across the galvanometer should be so adjusted that all excursions have about the same value. The following are a series of observations made by firing a bullet from a small breech-loading pocket-pistol through two wires set up (as in fig. 1) from one to four feet apart, the muzzle being close to the first wire. The accumulator was insulated with mica and shellac; its capacity was $\frac{1}{3}$ microfarad $\left(f=0.333 \times 10^{-6}\right.$ farad $)$; its leakage in fifteen minutes was only 1 per cent., and therefore its insulation resistance about 250,000 megohms. The discharging wire had a resistance of 100,000 ohms. The constant $(f r)$ was therefore $=0.0333$.

\begin{tabular}{|c|c|c|c|c|c|}
\hline \multirow{2}{*}{$\begin{array}{c}\text { Experi- } \\
\text { ment. }\end{array}$} & \multirow{2}{*}{$\begin{array}{c}\text { Range, } \\
d .\end{array}$} & \multicolumn{2}{|c|}{ Excursion of light. } & \multirow{2}{*}{$\begin{array}{c}\text { Time of flight, } \\
\text { calculated } \\
\left(\begin{array}{c}\left.\text { fr } \log _{\varepsilon} \frac{\mathbf{C}}{c}\right) \\
t\end{array}\right.\end{array}$} & \multirow{2}{*}{$\begin{array}{c}\text { Calculated } \\
\text { velocity of } \\
\text { shot, } \\
\frac{d}{t} .\end{array}$} \\
\hline & & C. & $c$. & & \\
\hline $\begin{array}{l}1 . \\
2 . \\
3 . \\
4 . \\
5 . \\
6 . \\
7 . \\
8 . \\
9 . \\
10 . \\
11 . \\
12 . \\
13 . \\
14 . \\
15 . \\
16 .\end{array}$ & $\begin{array}{c}\text { feet. } \\
1 \\
1 \\
1 \\
2 \\
2 \\
2 \\
2 \\
3 \\
3 \\
3 \\
3 \\
3 \\
4 \\
4 \\
4 \\
4\end{array}$ & $\begin{array}{c}\text { divisions. } \\
\mathbf{3 0 0} \\
300 \\
300 \\
300 \\
\mathbf{3 0 0} \\
300 \\
\mathbf{3 0 0} \\
299 \\
299 \\
299 \\
299 \\
299 \\
\mathbf{2 9 9} \\
299 \\
299 \\
\mathbf{2 9 9}\end{array}$ & $\begin{array}{c}\text { divisions. } \\
280 \\
281 \\
280 \\
251 \\
256 \\
260 \\
259 \\
240 \\
245 \\
250 \\
256 \\
246 \\
230 \\
229 \\
225 \\
231\end{array}$ & $\begin{array}{l}\text { second. } \\
0.0023 \\
0.0022 \\
0.0023 \\
0.0059 \\
0.0053 \\
0.0048 \\
0.0049 \\
00073 \\
0.0067 \\
0.0061 \\
0.0052 \\
0.0065 \\
0.0087 \\
0.0089 \\
0.0095 \\
0.0086\end{array}$ & $\begin{array}{c}\text { feet per sec. } \\
\mathbf{4 3 6} \\
\mathbf{4 5 7} \\
436 \\
\mathbf{3 4 0} \\
\mathbf{3 7 9} \\
\mathbf{4 2 2} \\
\mathbf{4 0 8} \\
\mathbf{4 0 8} \\
\mathbf{4 5 0} \\
496 \\
\mathbf{5 7 6} \\
460 \\
458 \\
451 \\
\mathbf{4 2 2} \\
\mathbf{4 6 7}\end{array}$ \\
\hline
\end{tabular}

A glance at these results shows that the separate observations were not more different from the mean value than could be well accounted for by the inequality of the charges of powder in the cartridges.

When the time to be determined is that which elapses between making and breaking a circuit, I have found that the apparatus may conveniently be arranged in principle as is shown in the sketch, fig. 2.

The poles of the battery are not required to be connected by 
the discharging resistance $r$ while charging the accumulator ; and therefore a very much lower value of $r$ may be employed than in using the preceding method, without fear of error. By way of illustration, $B$ is a block of metal or anvil against which the contact, $a$, is pressed in order to charge the accumulator, $\mathrm{A}$, by the battery $E$. The light hammer, $b$ (weighing about 1 ounce), is then suddenly struck against $B$ and allowed immediately to rebound off again. During the interval which elapses between the contact by $b$ and its interruption, or what may be Fig. 2.

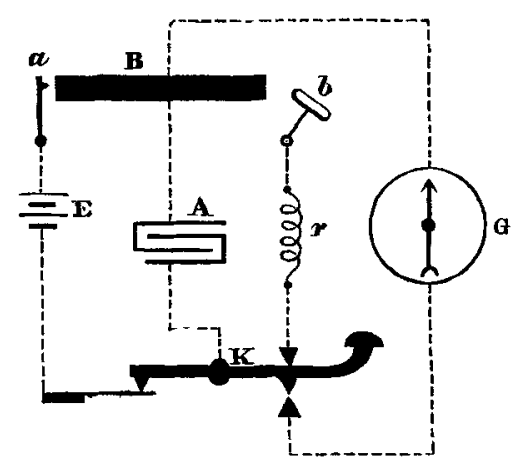
termed the electrical duration of the blow, the accumulator leaks through $r$; and the remainder is measured on the galvanometer $(G)$ by depressing the key $(K)$ as before. The same accumulator was used in these experiments as in the previous ones.

\begin{tabular}{|c|c|c|c|}
\hline \multicolumn{2}{|c|}{ Excursion of light-point. } & & $\begin{array}{c}\text { Duration of flow, } \\
\text { calculated } \\
\left(f r \log _{e} \frac{C}{c}\right) \\
t .\end{array}$ \\
\hline \begin{tabular}{c|c|c|} 
Initial charge, \\
C.
\end{tabular} & $\begin{array}{c}\text { Remainder, } \\
c .\end{array}$ & & \\
\hline & & ohms. & second. \\
308 & 265 & 1000 & $0 \cdot 000050$ \\
308 & 264 & 1000 & $0 \cdot 000051$ \\
308 & 269 & 1000 & $0 \cdot 000045$ \\
308 & 265 & 1000 & $0 \cdot 000050$ \\
307 & 261 & 1000 & $0 \cdot 000054$ \\
306 & 260 & 1000 & $0 \cdot 000054$ \\
306 & 262 & 1000 & $0 \cdot 000052$ \\
307 & 267 & 1000 & $0 \cdot 000047$ \\
\hline & & Mean $\ldots$ & $0 \cdot 000050$ \\
\hline
\end{tabular}

It now remains to be shown :-

1. That the results obtained by this method agree amongst themselves, and

2. That the intervals of time calculated by the formula agree with the observed time.

The observations made with the hammer and anvil (fig. 2) were sufficiently uniform to suggest that, by discharging the accumulator gradually by a series of blows of as nearly equal force as possible, the time of each blow might be regarded as 
an equal instalment of the whole time during which the discharge through the resistance-wire took place.

The following series of observations, with their calculated results, amply proves that this view was correct:-

\begin{tabular}{|c|c|c|c|c|c|}
\hline \multirow{2}{*}{$\begin{array}{c}\text { Number of } \\
\text { blows given } \\
\text { by hammer, } \\
n .\end{array}$} & \multicolumn{2}{|c|}{$\begin{array}{l}\text { Excursion of the light- } \\
\text { point. }\end{array}$} & \multirow{2}{*}{$\begin{array}{c}\text { Resistance } \\
\text { of dischar- } \\
\text { ging wire, } \\
r .\end{array}$} & \multicolumn{2}{|c|}{ Calculated time } \\
\hline & C. & $c$. & & $\begin{array}{l}\text { of dis- } \\
\text { charge, } \\
t .\end{array}$ & $\begin{array}{c}\text { of each blow, } \\
\frac{t}{n}\end{array}$ \\
\hline $\begin{array}{r}10 \\
9 \\
8 \\
7 \\
6 \\
6 \\
5 \\
4 \\
3 \\
2 \\
1\end{array}$ & $\begin{array}{l}311 \\
311 \\
311 \\
311 \\
311 \\
310 \\
310 \\
310 \\
309 \\
309\end{array}$ & $\begin{array}{l}109 \\
121 \\
139 \\
105 \\
120 \\
138 \\
128 \\
125 \\
118 \\
145\end{array}$ & $\begin{array}{c}\text { ohms. } \\
1500 \\
1500 \\
1500 \\
1000 \\
1000 \\
1000 \\
700 \\
500 \\
\mathbf{3 0 0} \\
\mathbf{2 0 0}\end{array}$ & $\begin{array}{c}\text { second. } \\
0 \cdot 000524 \\
0.0004771 \\
0 \cdot 000402 \\
0 \cdot 000362 \\
0 \cdot 000317 \\
0 \cdot 000269 \\
0 \cdot 000206 \\
0.000151 \\
0 \cdot 000096 \\
0 \cdot 000050\end{array}$ & $\begin{array}{c}\text { second. } \\
0 \cdot 000052 \\
0 \cdot 000052 \\
0 \cdot 000050 \\
0.000052 \\
0 \cdot 000053 \\
0.000054 \\
0 \cdot 000051 \\
0 \cdot 000050 \\
0 \cdot 000048 \\
0 \cdot 000050\end{array}$ \\
\hline & & & & Mean ... & 0.000051 \\
\hline
\end{tabular}

In 1872 I commenced a series of experiments with the view of comparing the results calculated by this method with the time given by some form of chronoscope. The difficulty I met with, however, was to find a chronoscope of sufficient sensibility to give a contact or series of contacts of known duration. For this purpose the late Sir C. Wheatstone, with the generous aid he always gave to any physical inquiry, placed in my hands an apparatus which had been very ingeniously designed and constructed for him some years before by Mr. Stroh for a different purpose; and with this apparatus, furnished with suitable electric contacts, I made several attempts to check the correctness of the formula*.

This apparatus consisted of a disk of metal with a heary rim, set in rotation by the force of a spring which was arrested by striking against an anvil, whilst a pointer turning with the disk struck a blow against the end of a small lever at some point of the revolution determined by its position. The duration of the contact was arranged to last from the instant when the impelling spring struck the anvil until the pointer on the disk struck the lever; and as it was assumed (and found) that the velocity at any point of a single revolution was practically uniform, the placing of the pointer enabled an interval of very small duration to be ensured. The results which I obtained, however, with this apparatus, although highly interesting,

* I was much indebted to the industrious aid which Mr. J. Rymer Jones rendered $m \Theta$ in these observations. 
were not concordant, there appearing to be a variable and rather considerable interval between the closing of the contact and the motion of any electricity in the circuit. This behaviour, which had induced Sir C. Wheatstone to lay the apparatus aside, induced me to regard it also as not sufficiently exact for the purpose for.which he had suggested that I might be able to use it.

Much occupation prevented me taking up this subject again until recently, when I recommenced by making a more careful study of this little contact-apparatus, and found the cause of its irregularity to be vibration due to the sudden stopping of the impelling spring. I therefore had it reconstructed so that each part was placed upon a separate base, and found that it then fulfilled all that could be desired of it.

The periphery of the rotating disk is divided into 500 equal parts; and as the finger or pointer is furnished with a nonius by which $\frac{1}{10}$ of a division may be accurately read, or $\frac{1}{5000}$ of the periphery, it follows that when the disk makes two revolutions per second, the finger may be placed to give a blow at any desired interval between 0.0001 and 0.5 second.

The force of the spring is adjusted as nearly as can be to give the requisite initial speed of rotation by observing the engraved divisions of the disk, which become visible in succession under the fibre of a small telescope when illuminated by the spark of an induction-coil, the primary circuit of which is opened and closed by a half-seconds' pendulum.

The way in which I have employed this apparatus for controlling the above method of electrically determining very small intervals of time is as follows:- The body of the disk $d d$ and spring are connected to one side of the mica accumulator, A, fig. 3. The spring $e^{\prime} e$, whilst trigged, rests in contact with a point $s$, connected with one side of the battery $\mathrm{E}$. The remaining sides of the accumulator and battery are connected together. In this position, therefore, the battery charges the accumulator. Contact $m$ is joined through the adjustable wire resistance $r$, and contact $n$ through the galvanometer $\mathrm{G}$, with the point of junction between battery and accumulator. On releasing the disk the spring $e$, leaving $s$, breaks the battery-circuit, and,

Fig. 3.

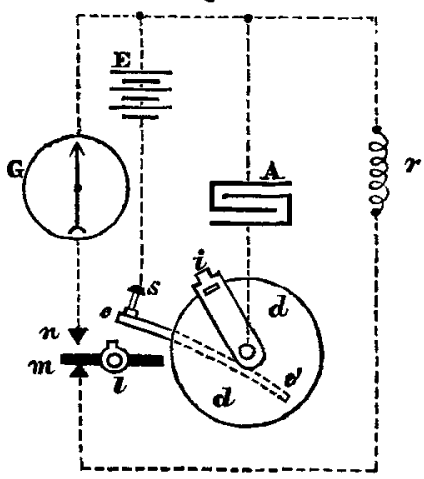


coming into contact with an anvil in electrical connexion with the support of the lever $l$, allows the charge of the accumulator to leak partially away through $m$ and $r$ until the pointer, $i$, rotating with the disk, strikes $l$ from $m$ to $n$, thereby stopping further discharge through $r$, and putting the accumulator to the galvanometer, which indicates the remaining electricity, $c$.

In the experiments which follow, the object was to compare the relation of the excursions $\left(\frac{C}{c}\right)$ as observed with the same relation calculated by the aid of the formula, on the assumption that the time-intervals as indicated by the index of the pointer on the disk were correct. The same accumulator was used as in the previous experiments. The battery consisted of two LeClanché cells. The galvanometer-coil was shunted by a wire whose multiplying-constant was $=3$ in reading the excursions due to the initial charges $\mathrm{C}$.

\begin{tabular}{|c|c|c|c|c|c|}
\hline \multirow{2}{*}{$\begin{array}{l}\text { Interval of } \\
\text { time by in- } \\
\text { dex of disk. }\end{array}$} & \multirow{2}{*}{$\begin{array}{c}\text { Discharging } \\
\text { resistance } \\
(r) .\end{array}$} & \multicolumn{2}{|c|}{$\begin{array}{l}\text { Excursions of needle } \\
\text { observed. }\end{array}$} & \multicolumn{2}{|c|}{$\frac{\mathbf{C}}{c}$. } \\
\hline & & o. & $o$. & Observed. & Calculated. \\
\hline $\begin{array}{l}\text { sacond. } \\
0.0002\end{array}$ & $\begin{array}{c}\text { ohms. } \\
500\end{array}$ & $\begin{array}{c}\text { divisions. } \\
232 \times 3\end{array}$ & $\begin{array}{c}\text { divisions. } \\
204\end{array}$ & $3 \cdot 41$ & \\
\hline $0 \cdot 0003$ & 700 & $232 \times 3$ & 206 & $\begin{array}{l}3 \cdot 41 \\
3 \cdot 38\end{array}$ & $\begin{array}{l}3 \cdot 32 \\
3 \cdot 62\end{array}$ \\
\hline $0-0004$ & 1000 & $233 \times 3$ & 226 & 3.09 & $\mathbf{3} \cdot 32$ \\
\hline 0.0005 & 1200 & $233 \times 3$ & 214 & $\mathbf{3} \cdot \mathbf{2 7}$ & $3 \cdot 49$ \\
\hline 0.0016 & 1600 & $283 \times 3$ & 228 & 3.06 & 3.08 \\
\hline 0.0007 & 1700 & $233 \times 3$ & 210 & 3.33 & $\mathbf{3} \cdot 44$ \\
\hline $0 \cdot 0008$ & 2000 & $234 \times 3$ & 216 & $3 \cdot 25$ & $3 \cdot 32$ \\
\hline 0.0009 & 2300 & $234 \times 3$ & 226 & $3 \cdot 11$ & $3 \cdot 23$ \\
\hline 0.001 & 2500 & $234 \times 3$ & 218 & $3 \cdot 22$ & $3 \cdot 32$ \\
\hline 0.002 & 5000 & $234 \times 3$ & 224 & $3 \cdot 13$ & $\mathbf{3} \cdot \mathbf{3 2}$ \\
\hline 0.003 & 7000 & $234 \times 3$ & 216 & $3 \cdot 25$ & $3 \cdot 62$ \\
\hline 0.004 & 10000 & $235 \times 3$ & 208 & $3 \cdot 39$ & $3 \cdot 32$ \\
\hline $0 \cdot 005$ & 12000 & $235 \times 3$ & 200 & $3 \cdot 52$ & $3 \cdot 49$ \\
\hline 0.006 & 14000 & $235 \times 3$ & 198 & $3 \cdot 56$ & $\mathbf{3} \cdot \mathbf{6 2}$ \\
\hline 0.007 & 37000 & $235 \times 3$ & 206 & $3 \cdot 42$ & $3 \cdot 44$ \\
\hline 0.008 & 20000 & $236 \times 3$ & 210 & $3 \cdot 37$ & $\mathbf{3} \cdot \mathbf{3 2}$ \\
\hline 0.009 & 23000 & $235 \times 3$ & 212 & $3 \cdot 33$ & $\mathbf{3 \cdot 2 3}$ \\
\hline 0.01 & 25000 & $237 \times 3$ & 215 & $3 \cdot 31$ & $3 \cdot 32$ \\
\hline 0.02 & 50000 & $236 \times 3$ & 213 & $\mathbf{3} \cdot \mathbf{3 3}$ & $3 \cdot 32$ \\
\hline 0.03 & 70000 & $233 \times 3$ & 196 & $3 \cdot 57$ & $3 \cdot 62$ \\
\hline 0.04 & 100000 & $231 \times 3$ & 208 & $3 \cdot 34$ & $3 \cdot 32$ \\
\hline 0.05 & 130000 & $232 \times 3$ & 217 & $3 \cdot 20$ & 3.17 \\
\hline 0.06 & 160000 & $236 \times 3$ & 230 & $3 \cdot 08$ & $3 \cdot 08$ \\
\hline 0.07 & 180000 & $235 \times 3$ & 219 & $3 \cdot 22$ & $3 \cdot 21$ \\
\hline 0.08 & 200000 & $235 \times 3$ & 210 & $3 \cdot 36$ & $3 \cdot 32$ \\
\hline 0.09 & 230000 & $235 \times 3$ & 218 & $3 \cdot 24$ & $\mathbf{3 \cdot 2 3}$ \\
\hline $0 \cdot 1$ & 250000 & $234 \times 3$ & 210 & $3 \cdot 34$ & $3 \cdot 32$ \\
\hline
\end{tabular}

It is evident from this Table that the agreement between the 
intervals adjusted mechanically and those calculated by means of electrical leakage is very close, and that the formula $\left(t=f r \log _{\varepsilon} \frac{\mathrm{C}}{c}\right)$ is not only applicable for slow discharges through very high resistances, but equally so for quick discharges through low resistances.

These two series of test-experiments I think show conclusively that this system affords results which, through a wide range of time-intervals, are comparable with each other-and, further, that within a small percentage these calculated intervals are correct.

In the method in which two circuits are broken, the discharging resistance is kept in circuit whilst the accumulator is being charged, on the assumption that the battery-resistance is so small in comparison with it that the potential of its poles is not thereby altered. This is theoretically evident; and the following observations of the instantaneous discharge when the batterypoles were connected by resistances of various values show that, until the discharging wire is reduced in resistance much below that which is required to be used in the method, no appreciable error is introduced.

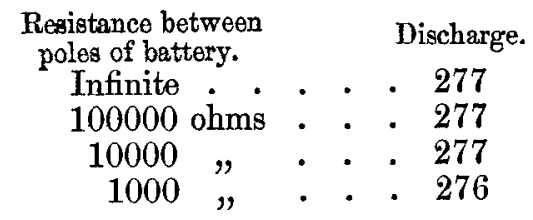

It is also assumed in both ways of working, that the time which elapses between the interruption of the dischargingwire and the closing of the galvanometer-circuit is insufficient to allow of leakage through the dielectric of the accumulator. The following experiment was made for the purpose of ascertaining the actual leakage of the accumulator for various periods of insulation :-

$$
\begin{array}{rrr}
\text { Instantaneous discharge } & \cdot & =275 \\
\text { Discharge after 1 minute } & \cdot & =275 \\
, \quad 15 \text { minutes } & \cdot & =272 \\
" \quad 30 \quad, & \cdot & =269
\end{array}
$$

It is evident, therefore, that, were even fifteen minutes allowed to elapse before taking the reading, the error through this delay would be only about 1 per cent. There is nothing, however, to prevent the reading being taken within a second or two. 
In employing this system I have found that there are certain precautions which it is necessary to keep in view. In the first place, it is desirable, in taking the readings of the excursions of the needle, to so adjust the resistance-wire that the value of $c$ is not too nearly the same as that of the initial charge $C$. When they are nearly of the same value, a very slight error of observation makes a material error in the result, because the difference of their logarithms may increase or decrease much more rapidly than the numbers themselves. On the other hand, the proportion between $\mathrm{C}$ and $c$ should not be too great; in other words, the accumulator should not be too empty when its reduced charge is observed. The electricity which flows from a battery into an accumulator (assumed to be perfectly insulated) is employed in two ways : (1) it suddenly charges the coatings inductively; and (2) it gradually polarizes or charges the dielectric material. When the charged coatings are connected through a small resistance, the coatings are first discharged suddenly, and the "diselectrification" or discharge of the dielectric (which commences at the same instant of time) goes on gradually. We should therefore be prepared to find a small quantity of electricity still in the accumulator long after the coatings have been discharged. This is more observable when the discharge takes place suddenly than when it takes place gradually (that is, through a high resistance), because in the latter case the diselectrification-current, which is very small in comparison with the discharge-current, has time to creep out with it unobserved.

This, however, has an effect only when the accumulator becomes very empty and the readings of $c$ are so small as to come within its disturbing influence. By selecting the discharging-resistance of such a value that the measured remainder from the accumulator is never less than one third or one fourth of the initial charge, all fear of error from this cause may be dismissed.

There are numerous applications in which the determination of time-intervals of very small duration may be found of practical value; and I think that this system may be depended upon.

In conclusion I must acknowledge the valuable assistance which I have had, both in arranging the apparatus and in making the observations, from $\mathrm{Mr}$. $\mathrm{M}^{\circ}$ Eniry.

25 Cumberland Terrace, N.W., February 1876. 